\title{
ANÁLISIS DEL CONTROL GUBERNAMENTAL EN LAS EMPRESAS PRODUCTIVAS DEL ESTADO A RAÍZ DE LA REFORMA ENERGÉTICA EN MÉXICO DE 2013*
}

\section{ANALYSIS OF GOVERNMENT CONTROL IN STATE PRODUCTIVE COMPANIES, DUE TO THE 2013 ENERGY REFORM IN MEXICO}

\section{Lauren Astrid GARCÍA MÁRQUEZ**}

\section{Isidro Andrés MENDOZA NORIEGA***}

RESUMEN: El presente estudio refiere al análisis de los cambios que conllevó la reforma energética de 2013 en materia de control gubernamental, dentro de los cuales se encuentra la nueva naturaleza de Pemex y la CFE como empresas productivas del Estado, adquiriendo un enfoque distinto en cuanto a sus ejes y actuaciones, lo que deriva en un nuevo esquema de vigilancia y auditoría, así como nuevos mecanismos de transparencia y rendición de cuentas. Dichos cambios trascendentales tienen la finalidad de fortalecer el sector energético y evitar la corrupción; sin embargo, no se han obtenido los objetivos planteados.

Palabras clave: rendición de cuentas, transparencia, control, auditoría, vigilancia, reforma energética, empresas productivas del Estado, Pemex, CFE.

* Artículo recibido el 24 de junio de 2019 y aceptado para su publicación el 21 de abril de 2020.

** ORCID: 0000-0002-5073-3697. Egresada de la Facultad de Derecho de la Universidad Nacional Autónoma de México; proyectista en el Área de Responsabilidades del Órgano Interno de Control en la Procuraduría Federal del Consumidor. Correo electrónico: astrid.gam.18@gmail.com.

*** ORCID: 0000-0002-0749-4854. Licenciado en derecho con mención honorífica egresado de la Facultad de Derecho de la Universidad Nacional Autónoma de México 2019; asistente de investigación en el Instituto de Investigaciones Jurídicas, UNAM, 2017-2019; asesor jurídico en la Dirección de Recursos Materiales y Servicios de la Segob, 2018-2019. Correo electrónico: aandresmendoza@hotmail.com.

Boletín Mexicano de Derecho Comparado, nueva serie, año LII, núm. 157, enero-abril de 2020, pp. 123-168.

Esta obra está bajo una Licencia Creative Commons Atribución-NoComercial-SinDerivar 4.0 Internacional, IIJ-UNAM. 
SUMARIO: I. Introducción. II. Rendición de cuentas, transparencia y fiscalización. III. Reforma energética de 2013. IV. Ejes en materia de control sobre las empresas productivas del Estado con base en la reforma energética de 2013. V. Naturaleza jurídica de Pemex y CFE. VI. Control de las empresas productivas del Estado. VII. Conclusiones. VIII. Bibliografia.

\section{INTRODUCGIÓN}

Para México, el sector energético representa un punto clave en el desarrollo del país. A pesar de las distintas reformas que se han realizado a lo largo de la historia en hidrocarburos y electricidad, se seguían presentando déficits importantes, que no permitían un mayor desarrollo en la materia y, a su vez, se originaban graves problemas de corrupción.

Es por ello que como parte de la reforma se encuentra el cambio en la naturaleza de las instituciones encargadas de llevar a cabo la actividad energética, es decir, la CFE y Pemex pasan de ser organismos descentralizados a ser empresas productivas del Estado con un gobierno corporativo.

Dos de los principales ejes con los cuales se les dio un enfoque diferente a las empresas productivas del Estado son: nuevos mecanismos de transparencia y rendición de cuentas y rediseño integral de los esquemas de vigilancia y auditoría. Con lo anterior se pretende que la CFE y Pemex brinden mayor seguridad en sus operaciones tanto en el ámbito nacional como en el internacional, siempre en el marco de la Constitución.

Además de dar confianza a la ciudadanía e inversionistas mediante un esquema de transparencia en sus contrataciones, pues anteriormente éste era un ámbito cerrado, ahora es público en gran medida, con ayuda de los órganos reguladores en materia energética, que les desempeñan un papel clave en la vigilancia de las actuaciones de las empresas productivas del Estado.

En el presente trabajo se analizarán los cambios más importantes realizados por la reforma en la CFE y Pemex en materia de control gubernamental; esto implica la forma en que operan dichas empresas productivas del Estado, así como sus nuevos mecanismos de transparencia, rendición de cuentas, auditoría y vigilancia; lo anterior es esencial para un desarrollo eficaz y eficiente del sector energético.

Estas herramientas de control dentro de las empresas productivas del Estado cobran aún más relevancia debido a los múltiples casos de corrup-

Esta obra está bajo una Licencia Creative Commons

Atribución-NoComercial-SinDerivar 4.0 Internacional, IIJ-UNAM.

Boletín Mexicano de Derecho Comparado, núm. 157, enero-abril de 2020, pp. 123-168. 
ción que se han suscitado dentro de ambas instituciones a través de los años, y que se habían presentado con mayor intensidad recientemente; por ejemplo, el caso Odebrecht en Pemex (López et al. 2018, 20-21); otro caso es el siguiente:

De 2003 a 2012, Reuters identificó más de 100 contratos, con un valor aproximado de 117 billones de dólares (8\% del ingreso total de Pemex en dicho periodo) que, de acuerdo a la ASF, presentaban graves irregularidades. Dichas incluían sobrevaluaciones de contratos, empleados fantasmas, pagos por servicios no recibidos, conflictos de intereses, etc[étera]. Entre 2008 y 2012, la ASF dio a Pemex 274 recomendaciones para obtener reparaciones por las pérdidas de los 6 contratos cuestionados. Pemex emitió respuestas a 267 de las mismas, mas sólo acató tres de ellas (Toledo 2016, 5).

La CFE no se ha escapado de los actos de corrupción

... de acuerdo al INAI, en los últimos 15 años, más de 40 funcionarios de la CFE han recibido multas de la SFP por participar en actos de corrupción. Éstas suman más de 80 millones de dólares. Pero estas medidas parecen ser puramente simbólicas ya que a la fecha tan solo se han pagado 830 dólares (Toledo s. d., 6).

Así, se pueden enumerar una gran cantidad de actos de corrupción dentro de ambas empresas productivas del Estado; es por ello que se necesita el fortalecimiento de los medios de control dentro de las mismas.

A pesar de que la reforma energética tuvo lugar hace algunos años, el presente estudio resulta interesante, debido a que no existen trabajos que se encarguen del estudio específico y detallado de esta parte de la reforma. Y tratándose de una actividad de tal relevancia como lo es el control de un sector dentro del Estado, su relevancia a pesar del paso de los años no es un tema menor, pues se trata de una actividad constante. De la misma forma, son escasas las investigaciones que abordan con detenimiento la corrupción y/o los mecanismos de control y rendición de cuentas dentro de las empresas productivas del Estado.

Cabe destacar que la transparencia y rendición de cuentas, al ser herramientas esenciales de control, juegan un papel de suma relevancia en la reforma, y se sitúan como uno de los principales objetivos de ésta; es por ello que se examinará si se ha logrado cumplir o no con estos estándares a la luz de las principales teorías en torno al tema. 


\section{RENDICIÓN DE GUENTAS, TRANSPARENGIA Y FISCALIZAGIÓN}

Rendición de cuentas y transparencia son temas que contribuyen de forma importante en el desarrollo y fortalecimiento democrático de un Estado de derecho, en vista de que son mecanismos a través de los cuales los gobernantes proporcionan información de sus acciones, con la finalidad de evitar la opacidad en el ejercicio del poder. Con base en estos instrumentos se puede evaluar el desempeño de los servidores públicos y de la gestión gubernamental, de donde resulta fundamental que un Estado los promueva en todas las áreas del quehacer público.

En la actualidad, "Fiscalización, control y auditoría gubernamental son conceptos que se consideran trascendentales por su relación con la corrupción y, por lo tanto, la creciente pérdida de confianza en las instituciones estatales" (Peralta 2015, 108). A los tres conceptos enunciados en la cita bien podríamos agregar el de rendición de cuentas, que se manifiesta como "una efectiva victoria sobre la corrupción sistémica y específica y [contribuye a] acabar con la impunidad" (Vega 2018, 101), ya que proporciona elementos para erradicar problemas, como corrupción, y ayuda a mejorar el desempeño de los servidores públicos.

La primera vez que se institucionalizó la rendición de cuentas fue en Francia, con la Declaración de los Derechos del Hombre y del Ciudadano de 1789; se establece en el artículo 15 de este documento: "La sociedad tiene derecho a pedir cuentas de su gestión a cualquier agente público". Esta disposición constituye uno de los primeros esfuerzos por acotar la actividad de los gobernantes a medidas de control, para evitar un uso desmedido, arbitrario y discrecional del poder, como se había ejercido a través de las monarquías dictatoriales, en donde se concentraba en una sola persona todo el poder y la fuerza de decisión del Estado. Cabe aclarar que se pueden rastrear antecedentes de la rendición de cuentas desde las democracias de Atenas y Grecia. En el caso de Atenas, existían cinco instituciones: ostracismo, euthinay, eisangelia, aphofasis y graphe paranomon (Ugalde 2015). Básicamente estas instituciones se encargaban del control en cada una de las áreas del Estado, como materia política, control de las cuentas públicas, de la administración y políticas públicas. Existen otros ejemplos de los antecedentes del control dentro del Estado, como los siguientes: 
... instituciones como la partida doble - que ya aparece en algunos libros en 1340, refinada posteriormente por Luca de Boigo Paciolus, mejor conocido como fray Luca Pacioli (1445-1517), en su libro Suma de aritmética, geometría $y$ contabilidad - van a ser el antecedente de los modernos auditores y de la contabilidad. La Magna Charta de 1215 tiene como eje motor los abusos del monarca inglés. La Ilustración, con su llamado a la razón, pone el acento en el control del poder. La teoría de la división de poderes, que en esta época adquiere relevancia, tiene como propósito que el poder controle al poder (Márquez 2003, 14)

El párrafo citado enuncia algunos de los acontecimientos e instituciones más importantes que abonaron en el control y la rendición de cuentas desde diversas áreas del Estado, como el aspecto financiero y el control parlamentario.

Ahora bien, en el México antiguo también existen algunos antecedentes en materia de control y rendición de cuentas:

... el control general de todos los tributos que formaban la Hacienda Pública correspondía, como ya hemos dicho, al Cihuacóatl (funcionario civil, especie de alter ego del rey), que cuidaba de su distribución y buen empleo, contando para ello con autoridad propia, de tal modo que el rey no podía disponer a su arbitrio de los caudales del reino, pues éstos debían dedicarse precisamente a lo que de antemano y por bien público estaba determinado, lo que revela un gran progreso administrativo para aquellos tiempos y aquellas circunstancias (Lanz 1987, 28).

Los hechos descritos en el párrafo anterior nos muestran que los aztecas contaban con sistemas de control en diferentes aspectos; específicamente, el párrafo anterior nos habla del control en materia tributaria. Es así como tanto a nivel internacional como dentro de la historia política y cultural de los pueblos prehispánicos en el caso específico de México se sitúan diversas manifestaciones de la institucionalización del control dentro de los Estados.

La rendición de cuentas es un término que se castellaniza de la palabra anglosajona accountability. Dicho concepto no tiene una traducción literal al español, puesto que es entendido como responsabilidad o rendición de cuentas; éste es su intento de traducción más acertado, puesto que también ha sido teorizado como transparencia, pero en menor medida, 
"el diccionario Merriam-Webster explica que el termino accountability se comenzó a usar a partir de 1770 para hablar del caso en que exista alguna persona o institución que es responsable por el cumplimiento de ciertos deberes de los que debe dar cuenta a una autoridad" (Romero 2019). En las siguientes líneas veremos que la accountability se encuentra más alejada del término "transparencia", a pesar de tener una cierta relación con el concepto. Andreas Schedler es uno de los teóricos que más ha contribuido al respecto. Schedler (2008) conceptualiza el término dividiéndolo en dos dimensiones; por un lado, answerability, que entraña la obligación de los funcionarios públicos de informar respecto de sus decisiones y justificarlas; por otro lado está la enforcement, que señala la capacidad de sanción sobre los servidores públicos que hayan violado alguno de sus deberes. De tal forma que Schedler construye lo que denominó "los tres pilares de la rendición de cuentas", que constituyen a la vez sus etapas.

Como primer momento está la información y justificación, que son parte de la responsabilidad que tiene el servidor público respecto de sus actuaciones. En esta etapa se proporciona la información del actuar del funcionario y posteriormente se otorgan las razones de por qué se actuó de dicha manera, las cuales deben tener bases sólidas de motivación y fundamentación, puesto que el servicio público está restringido a realizar sólo aquello que la ley permite; por tanto, sus actos deben estar apegados a la legalidad, además de aplicar criterios de eficacia y eficiencia en sus decisiones.

En un segundo momento se encuentra la posibilidad de sanción, etapa que cierra el ciclo de la rendición de cuentas. Esta fase entraña la función de establecer medidas de sanción efectivas a los funcionarios que hayan transgredido alguno de los deberes que los rigen: estas transgresiones serán detectadas como consecuencia de la práctica de la primera etapa. Es cierto que no en todos los sistemas se previenen las sanciones, lo que da paso a la conceptualización de rendición de cuentas blanda y rendición de cuentas dura.

Aquellos sistemas que prevén medidas de sanción ante el actuar irregular de los servidores y políticos en el ejercicio de sus funciones constituyen una rendición de cuentas dura, pues la sanción representa un incentivo o, por el contrario, un castigo para la conducta gubernamental. En cambio, si no existen sanciones y únicamente se emiten observaciones y 
recomendaciones, o el proceso se colma con la entrega de información, estamos hablando de una rendición de cuentas blanda.

La esencia de la rendición de cuentas se encuentra en la intención de disciplinar al poder y prevenir sus abusos" (Salgado 2006, 138). Para estos efectos también podemos referirnos a la idea de control; sin embargo, es importante diferenciar la rendición de cuentas del concepto de control, puesto que este último "pretende eliminar o minimizar los márgenes de decisión de funcionarios y políticos" (Schedler 2008, 91). El control es un término más amplio, y bien podríamos entender a la rendición de cuentas como una de las herramientas, pero no como conceptos análogos.

El control es un concepto amplio, que tiene su aparición y desarrollo anterior al de rendición de cuentas. El control surge desde que se crean las primeras formas de organización. Manuel Aragón señala que el control no tiene un sentido unívoco, puesto que se puede materializar a través de diversos medios, "bajo las diversas formas (parlamentaria, judicial, social, etcétera) del control del poder y bajo las diversas facetas (freno, vigilancia, revisión, inspección, etcétera) que tal control puede revestir" (Aragón 2002, 97).

Etimológicamente la palabra control se identifica con las voces latinas inspectio, inquisitio, espectatio, -onis y judicium. Con ellas se alude a diversas cuestiones que se identifican con examen, limitación, regulación, dispositivo, verificación, tutela, dominio y supremacía (Márquez 2005, 11).

Una forma de entender el control es por medio de la clasificación hecha por Karl Loewenstein (1976), quien los divide en controles intraorgánicos y controles interorgánicos. Los primeros son los que se llevan a cabo por el mismo sujeto del control; es una forma de autocontrol; los segundos son los que se llevan a cabo entre diversas dependencias o instituciones.

Como ya se ha mencionado, el control surge como una necesidad desde que se crea el Estado y la división de poderes; por ello, se analizará la clasificación del control desde el ámbito de cada uno de ellos:

- Control legislativo o político: "este control es el que ejerce el órgano encargado de expedir las leyes" (Márquez 2005, 23), que se materializa de diversas formas, en un principio por medio de la expedición de leyes y también por medio del control presupuestal y el político. 
- Control judicial o jurisdiccional "lo realizan los tribunales encargados de impartir justicia y se relaciona con la actividad de esos órganos" (Márquez 2005, 24). Esta forma de control se ejerce mediante toda la serie de recursos procesales en ley que permiten frenar abusos o actos que contraríen el Estado de derecho.

- Control administrativo. Esta forma de control es la que se ejerce dentro de la administración pública del Estado, con el objetivo de limitar las funciones de los diferentes entes dotados de poder y de capacidad de decisión dentro de las diversas actividades públicas.

Finalmente, se tomará la clasificación propuesta por María de la Luz Mijangos (1996), pues es de vital importancia en cuanto hace a la actividad financiera del Estado dentro de la administración pública. Las empresas productivas del Estado forman parte de la administración; por lo tanto, esta clasificación nos será de gran ayuda.

a) Control interno. Se puede definir como aquel que debe realizar la propia administración; esto es, un órgano especializado encuadrado dentro del Poder Ejecutivo, pero situado jerárquicamente en una posición superior, o por lo menos no dependiente orgánica ni funcionalmente de ninguna secretaría, con el propósito de investigar, comprobar, y en su caso, informar, sobre la legalidad, eficacia, objetivos, resultados, etcétera, del gasto público.

b) Control externo de carácter político. El control externo tiene dos vertientes: la política y la jurisdiccional. Cuando se lleva a cabo por el Poder Legislativo en ejercicio de las facultades que constitucionalmente le están asignadas, se le conoce como control político.

c) Control externo jurisdiccional. Este tipo de control lo ejerce un órgano de carácter jurisdiccional, ya sea que se encuentre ubicado dentro del Poder Legislativo - en cuyo caso conserva, no obstante, plena independencia en el desarrollo de su función-, o se trate de una institución especializada, situada orgánica y funcionalmente dentro del Poder Judicial.

Es así que la fiscalización, transparencia y rendición de cuentas constituyen herramientas importantes para el control gubernamental. A pesar de existir una diversidad de formas y facetas de control, todas ellas tienen 
la finalidad de evitar el uso arbitrario y desmedido del poder, finalidad que se persiguió desde las revoluciones del siglo XVIII en contra de los gobiernos absolutistas.

Ahora bien, dentro del Estado están obligados a rendir cuentas todos los funcionarios y políticos que desempeñan alguna actividad dentro del Estado, puesto que se les han encomendado actividades de representación y respecto de las cuales deben reflejar ciertos resultados. En cuanto a quien exige cuentas, en primer lugar podemos decir que corresponde a la sociedad este derecho; así, hablamos de la rendición de cuentas vertical; pero dada la complejidad de la estructura gubernamental de los Estados actuales, se tienen que implementar mecanismos a través de los cuales se desempeñe o se ejerza este derecho entre entes que forman parte de la propia estructura estatal; en este último caso hablamos de la rendición de cuentas horizontal (Fox 2008). "En los ámbitos administrativo y financiero, las tareas de rendición de cuentas muchas veces se encomiendan a agencias públicas especializadas, tales como defensores del pueblo, cortes administrativas, oficinas de auditoría y agencias anticorrupción" (Schedler 2008, 98). En el caso de nuestro estudio, analizaremos que la función de rendición de cuentas es desempeñada por el modelo de auditoría, principalmente.

La transparencia se constituye a partir de la existencia de información, pero además de los distintos mecanismos o instrumentos que se diseñan e implementan para acceder a la misma. En otras palabras, no podemos hablar de transparencia sin que existan los medios necesarios para poder acceder a los datos que reflejen las acciones de la actividad gubernamental, "la transparencia, conceptualizada en palabras más simples, consiste en un mecanismo de publicidad y acceso a la información gubernamental sin un destinatario específico ni un formato especial" (Brizio 2008, 212).

Asimismo, la transparencia existe en la medida en que se dé publicidad de las acciones de gobierno, "la idea de publicidad conecta las bases normativas del proceso democrático y de la rendición de cuentas" (Monsiváis 2005, 40); es así que podemos entender a la transparencia como la primera fase que constituye el proceso de rendición de cuentas; esto es, la presentación de información, aunque cabe aclarar que la transparencia va más allá de este derecho. El acceso a la información lo constituye el derecho que tiene todo ciudadano a conocer la información producida y controlada por los poderes públicos (Merino 2008). La transparencia 
se genera a partir de los datos e información que pueden ser conocidos por un público, pero además debe servir para que la misma institución o ente del Estado que la genera, se autoevalúe y con base en ello mejore sus prácticas; todo lo anterior acompañado de los mecanismos necesarios para generar y dar a conocer los datos.

La transparencia puede presentarse de diversas formas, según los mecanismos de generación y acceso a la información que se proporcione. Existe una clasificación de la transparencia en dos tipos: opaca y clara.

La transparencia opaca "se refiere a las formas de difusión de información oficial que no revelan cómo se desempeñan las instituciones en la práctica, ya sea en términos de cómo se toman decisiones o de cuáles son los resultados de sus acciones" (Fox 2008, 191). En esta clasificación cabe hacer una crítica, debido a que estos términos resultan contradictorios desde la simple definición de cada una de las palabras; por un lado, transparencia puede ser definida como algo que tiene la cualidad de ser transparente; es decir, "claro, evidente, que se comprende sin ninguna ambigüedad" (RAE). Por otra parte, "opaco" se define como algo "que impide el paso a la luz u oscuro" (RAE). Por ello, podemos concluir que hay una clara contradicción, y en nuestra opinión esta clasificación resulta confusa.

Es cierto que puede existir el caso en el cual dentro de un Estado haya nula difusión de la información o mecanismos adecuados para poder acceder a ella, y casos en que haya Estados que provean los mecanismos necesarios para difundir información y exista en circulación información, pero que ésta se encuentre tergiversada o que únicamente se arrojen datos para simular que se cumple con una obligación, cuando en realidad esta información no refleja el verdadero actuar de las instituciones del Estado. Para este último caso el resultado viene a ser el mismo que si no existiera información; es decir, si no existe transparencia por parte del Estado, ¿de qué le puede servir a los ciudadanos una cantidad infinita de datos en circulación cuando no reflejan las verdaderas acciones y resultados de las instituciones del gobierno? Por tanto, sería incorrecto hablar de una transparencia opaca.

La transparencia clara "se refiere tanto a programas que dan a conocer información confiable y accesible sobre el desempeño institucional, precisando las responsabilidades de sus funcionarios, particularmente en 
lo relativo a la toma de decisiones, así como el destino real de sus recursos" (Fox 2008, 191).

Para que la transparencia sea efectiva no basta con proporcionar información y pensar que se están cumpliendo sus objetivos con este sólo hecho, sino que la información divulgada debe corresponder de forma efectiva con las decisiones y acciones que se toman dentro de la esfera gubernamental, de manera que no se tergiverse y manipule la información; así, "se asume que la rendición de cuentas y la transparencia hacen visible el trabajo de las organizaciones" (Sepúlveda 2005, 140), "se puede a través de los mecanismos de transparencia difundir los logros, difundir las acciones, lo valioso y los importantes de esas decisiones" (Luna 2012, 42), estas ideas son de relevancia, sobre todo para Pemex, pues como se analizará más adelante, uno de los motivos de la reforma es reforzar la credibilidad en dicha institución.

La fiscalización es otra de las herramientas de control sobre la administración pública, generalmente en lo que respecta al control de recursos públicos; se puede decir que "es la acción por la cual se evalúan y revisan las acciones de gobierno, considerando su veracidad, razonabilidad y apego a la ley" (Adam y Becerril 2003, 15). Esta forma de control se realiza $e x$ post, es decir, una vez que se han llevado a cabo los actos a evaluar.

Mauricio Merino señala al respecto que "es preciso asegurar, mediante los procesos de fiscalización, que, después de todos los controles existentes, el dinero público se gastó de forma honesta y no se desviaron recursos para intereses privados" (Merino et al. 2016, 104). Mauricio Merino propone a la fiscalización como la etapa final del proceso de la rendición de cuentas.

La fiscalización incluye la "comprobación de la legalidad de los actos públicos, su eficiencia, eficacia, el cumplimiento de los programas de gobierno y recientemente, el fincamiento de responsabilidades" (Manjarrez 2003, 57). La fiscalización es importante porque constituye la herramienta mediante la cual se sigue la legalidad de los actos públicos principalmente relacionados con el manejo de recursos, desde el momento de su asignación hasta la ejecución de los mismos:

La fiscalización se realiza mediante el estudio y análisis de documentación e información relativa al ejercicio, procedimientos y operaciones de los órganos del gobierno, consiste en el control de la actividad financiera pública de 
conformidad con los principios establecidos y plasmados en la Constitución Política de los Estados Unidos Mexicanos y demás ordenamientos que de ésta emanan (Medina 2015, 180).

Podemos ver claramente en la idea anterior que la fiscalización es una herramienta de gran peso en el control relativo al manejo de recursos públicos por parte del Estado. Siguiendo la argumentación de Medina Estrada, cabe resaltar una idea más:

En México, la fiscalización implica la existencia de órganos internos de control en las dependencias y entidades de la administración pública federal, además de la Auditoría Superior de la Federación, ya que en conjunto hacen posible la revisión de las actividades y operaciones que realizan los poderes de la Unión en los tres ámbitos de gobierno, lo cual permite conocer el desempeño de las instituciones bajo los criterios de eficacia, eficiencia y economía (Medina 2015, 180).

Resulta interesante, debido a que el autor identifica a la fiscalización en México por medio de las principales instituciones que se encargan de llevar a cabo esta tarea. Para efectos de las empresas productivas del Estado, analizaremos en los apartados posteriores que estos principios se ven modificados con la nueva reforma.

Es así que podemos observar la relación tan estrecha que existe en los tres conceptos analizados, con regularidad se entienden y explican en su conjunto. "El efecto de la Fiscalización bajo la perspectiva de desarrollo institucional se aborda a la luz de la aplicación del gasto público bajo el esquema de resultados y frente al ejercicio de transparencia y rendición de cuentas" (Aguirre 2015, 149 y 150). Todos estos temas tienen la finalidad de contribuir a un control efectivo sobre la administración pública, y principalmente con ello evitar prácticas de corrupción, y conductas contrarias a las disposiciones legales que rigen el actuar de las instituciones y de los servidores públicos.

Dentro del tema de fiscalización es pertinente hablar de la auditoría, que se conforma como uno de los instrumentos que a su vez tiene la fiscalización para desempeñar los procesos de evaluación y revisión de las acciones gubernamentales, "es una función que tiene como objetivo la práctica o realización de una revisión” (Adam y Becerril 2003, 91); a su vez, "la auditoría entendida como el proceso de revisión, cae dentro de 
la rendición de cuentas horizontal, ya que su ejecución se realiza a través de instituciones específicas, como la Secretaría de la Función Pública y la Auditoría Superior de la Federación" (Brizio 2008, 214).

A nivel internacional se han reconocido diversos tipos de auditoría, principalmente existen tres modalidades:

- Auditoría de cumplimiento. "Analiza en qué medida la entidad auditada observa las reglas, las leyes y los reglamentos, las políticas, los códigos establecidos o las estipulaciones acordadas por ejemplo en un contrato o en un convenio de financiación" (ISSAI 4100 s. d.).

- Auditoría financiera. "Evaluación independiente, reflejada en una opinión de garantías razonables, de que la situación financiera presentada por una entidad, así como los resultados y la utilización de los recursos, se presentan fielmente de acuerdo con el marco de información financiera" (Glosario de términos de las Directrices de auditoría financiera de la INTOSAI 2010, 57).

- Auditoría de desempeño. Se entienden "como una revisión objetiva y confiable que permite conocer si las políticas públicas operan bajo los principios de eficacia, eficiencia y economía" (Tipos de auditoría, ASF).

Este tipo de revisiones ayudan a conocer cómo se está desempeñando la actividad gubernamental y hacer una evaluación de la medida en que se cumplen los parámetros establecidos para acercarnos a los objetivos planteados. Los órganos de vigilancia, ya sea internos o externos, públicos o privados, cuentan con dos grandes funciones: por un lado, la verificación de los recursos, esto es, respecto de la cuestión presupuestaria y su correcta utilización; y por la otra, la verificación del desempeño satisfactorio de las funciones por parte de las personas que integran la organización o institución (Peralta 2015, 111). Es así que dentro de la administración pública en México se han creado mecanismos de auditoría interna y externa, modelo que utilizan actualmente las empresas productivas del Estado, además de estar sujetas al control interno y externo de la administración pública.

Entender el concepto de auditoría será vital para comprender la temática desarrollada en este trabajo, dado que las empresas productivas del Estado tienen a la auditoría como su principal forma de control interna. 
Por último, resulta necesario cuestionarse si estos mecanismos son los ejes adecuados para conducir la actividad estatal, y muy específicamente en el control de las empresas productivas del Estado, puesto que como se revisará más adelante, ciertos principios, como el de la fiscalización o control interior y exterior, se modificaron con la reforma energética, y se ha creado un nuevo sistema de vigilancia. En cuanto al control de las actividades dentro del Estado, se puede considerar la siguiente idea:

el adecuado y escrupuloso manejo de los recursos públicos, el respeto a la legalidad, el combate a la corrupción, la mejora de procesos y servicios, y el desarrollo de una auténtica cultura de transparencia y rendición de cuentas, son hoy condiciones indispensables para la gobernabilidad democrática y para la integración de la ciudadanía a las tareas de mejora del entorno comunitario (Morgan 2008, 67).

Por ello, la transparencia, la rendición de cuentas, la fiscalización y la auditoría, hoy en día son procedimientos que acompañan en todo momento el quehacer de la administración pública. El Estado en la actualidad se conforma por una pluralidad de sujetos que son tomadores de decisiones; esto es, entrañan poder y autoridad; por tanto, estas decisiones deben ser vigiladas y conducidas para que se realicen a efecto de procurar el bien de la sociedad, así como la satisfacción de necesidades y el buen desempeño del Estado. Es importante que no perdamos la brújula, debemos exigir en todas las áreas del Estado este tipo de mecanismos que ayudan a la evaluación, medición del desarrollo y funcionamiento de las instituciones, cualquiera que sea la naturaleza y forma que éstas puedan tomar. A lo largo de la presente investigación se podrá analizar si estos mecanismos son convenientes en el desarrollo de las actividades de la empresa productiva del Estado, y la forma en que se están llevando a cabo a partir de la reforma de 2013.

\section{REFORMA ENERGÉTICA DE 2013}

La reforma energética de 2013 ha sido una de las mayores reformas de los últimos años debido a su complejidad política y legislativa, además de suponer un gran cambio para el sector energético. Lo anterior, con la finalidad de incrementar la competitividad y la productividad de México

Esta obra está bajo una Licencia Creative Commons

Atribución-NoComercial-SinDerivar 4.0 Internacional, IIJ-UNAM.

Boletín Mexicano de Derecho Comparado, núm. 157, enero-abril de 2020, pp. 123-168. 
mediante una apertura con transparencia, administración y rendición de cuentas adecuadas.

Cabe destacar que el sector energético mexicano se divide en dos grandes rubros: hidrocarburos y electricidad, mismos que toma en cuenta la reforma energética, teniendo los siguientes antecedentes históricos:

El sector de hidrocarburos, de acuerdo con Pedro Joaquín Coldwell (2014), se puede dividir en tres grandes momentos:

a) En la Constitución de 1917 se realizó la primera nacionalización del petróleo, en la cual se estableció el dominio directo de la nación sobre los hidrocarburos del subsuelo, propiciando la participación del sector privado en la exploración y extracción de éstos a través de concesiones.

b) El presidente Lázaro Cárdenas, mediante decreto publicado el 19 de marzo de 1938 en el Diario Oficial de la Federación (DOF), expropió las instalaciones de las compañías petroleras; posteriormente, el 7 de junio del mismo año se creó Petróleos Mexicanos (Pemex), por lo que en 1939 se aprobó una segunda Ley Reglamentaria del Artículo 27 en el Ramo del Petróleo (LRA27RP), en la que se prohibieron las concesiones, lo cual cambió con la abrogación de dicha Ley y la creación de una tercera, que estableció la participación de compañías privadas mediante contratos de riesgo. Finalmente, en 1940 se reformó el artículo 27 de la Constitución, con el cual el gobierno mexicano asumió el "monopolio" de la exploración, explotación, refinación y distribución del petróleo y sus derivados.

c) En 1958, el Congreso aprobó una cuarta Ley Reglamentaria del Artículo 27 en el Ramo del Petróleo, "la nueva Ley estableció el sistema de propiedad de la nación sobre el petróleo y otros hidrocarburos, además del monopolio público en el sector que incluyó todas las actividades relativas a la construcción y operación de infraestructura" (González 2017, 55). Por lo que en 1960 se reformo el artículo 27 constitucional, que estableció que no se otorgarían concesiones ni contratos ni sustitución de éstos.

En lo referente al sector eléctrico, la Comisión Federal de Electricidad fue creada por ley en 1937 "con el objeto de organizar y dirigir el sistema nacional de generación, transmisión y distribución de energía eléctrica" 
(González 2017, 73), y no fue sino hasta 1949 cuando se emitió el decreto en el que se estableció con las bases de su funcionamiento. Sin embargo, compartió la actividad de distribución con la hoy extinta Compañía de Luz y Fuerza del Centro.

En 1960, el presidente Adolfo López Mateos inició el proceso de nacionalización de la industria eléctrica con la compra de acciones a las principales empresas eléctricas extranjeras que operaban en el país, lo cual concluyó con la reforma al artículo 27 constitucional, con el cual la generación de energía eléctrica estuvo exclusivamente a cargo del Estado.

Durante 1992 se modificó la Ley del Servicio Público de Energía Eléctrica, que permitió la participación de la inversión privada en la generación de electricidad no destinada a la prestación de un servicio público mediante permiso otorgado por la Secretaría de Energía, por lo que al año siguiente se expidió el reglamento correspondiente a dicha Ley.

Con los antecedentes anteriores, y al observar el rezago en materia de hidrocarburos y electricidad que México tenía, se llegó a la conclusión de realizar una reforma energética radical que diera como resultado un país eficaz y eficiente. Sin embargo,

... para ello, había que alcanzar un consenso entre las diferentes fuerzas políticas y los principales actores sociales y económicos, con el fin de identificar las coincidencias en las distintas visiones sobre la realidad energética en México y las necesidades del país en la materia. Este complejo acuerdo se logró gracias al Pacto por México (Vázquez 2015, 5).

El Pacto por México, compuesto por cinco acuerdos nacionales, fue el instrumento político clave para llevar a cabo la reforma energética; se firmó el 2 de diciembre de 2012 por el presidente Enrique Peña Nieto y los dirigentes de las tres principales fuerzas políticas del país: PRI, PAN y PRD; sin embargo, este último abandonó el Pacto el 28 de noviembre de 2013. Cabe destacar que "como parte de los acuerdos para el crecimiento económico, empleo y competitividad se incluyeron siete compromisos específicos para concretar una reforma energética" (Gallardo 2014, 21).

Uno de los principales motivos que impulsó la reforma fue el hecho de que existía mayor inversión en la búsqueda y extracción de petróleo, pero con menor producción, debido a que el petróleo de fácil acceso se está agotando, y las reservas probadas para diez años de producción se 
ubican en aguas profundas del Golfo de México. Sin embargo, para seguir explorando nuevas áreas de explotación se necesita de mayor inversión y tecnología avanzada, además de que no es conveniente que la empresa estatal (Pemex) absorba el riesgo total. De igual manera, disminuye la productividad de los pozos en los que se encuentra gas natural, por lo que se incrementa la importación de éste.

Aunado a lo anterior, se consideró como parte de la reforma hacendaria la modificación el régimen fiscal bajo el que operaba Pemex, sustentado en derechos rígidos para ser modificado de tal manera que los derechos a pagar sean menores y "el remanente de ese pago de derechos podrá ser reinventado en la empresa o una parte podrá ser transferida al presupuesto" (Proyecto de iniciativa de reforma a los artículos 27 y 28 de la CPEUM del Ejecutivo federal 2013, 14) permitiendo que la empresa tenga mayor competitividad.

Por otro lado, en el sector eléctrico, la Comisión Federal de Electricidad (CFE) tenía una cobertura del 98\%, pero con tarifas altas, y 2\% pendiente a electrificar, lo cual se complicó, debido al déficit financiero con el que empezó a operar en 2012. En este aspecto, la reforma busca disminuir los costos de la energía eléctrica mediante la operación de un mercado eléctrico, establecer el acceso universal y avanzar en la transición energética hacia energías limpias.

Los objetivos de la reforma energética son:

- Mantener la propiedad de la nación sobre los hidrocarburos que se encuentran en el subsuelo.

- Modernizar y fortalecer, sin privatizar, a Pemex y a la Comisión Federal de Electricidad como empresas productivas del Estado 100\% mexicanas.

- Reducir la exposición del país a los riesgos financieros, geológicos y ambientales en las actividades de exploración y extracción de petróleo y gas.

- Permitir que la nación ejerza, de manera exclusiva, la planeación y control del sistema eléctrico nacional, en beneficio de un sistema competitivo que permita reducir los precios de la luz.

- Atraer mayor inversión al sector energético mexicano para impulsar el desarrollo del país. 
- Contar con un mayor abasto de energéticos a mejores precios.

- Garantizar estándares internacionales de eficiencia, calidad y confiabilidad de suministro, transparencia y rendición de cuentas.

- Combatir de manera efectiva la corrupción en el sector energético.

- Fortalecer la administración de los ingresos petroleros e impulsar el ahorro de largo plazo en beneficio de las generaciones futuras.

- Impulsar el desarrollo con responsabilidad social y proteger al medio ambiente (Reforma energética 2013,3).

El primer partido en presentar su propuesta fue el PAN, el 31 de julio de 2013: la propuesta consistía en reformar los artículos 25, 27 y 28 de la Constitución; destacaba el permitir el otorgamiento de concesiones para la exploración y explotación de hidrocarburos, y un principio de carácter ambiental para desarrollar estrategias y programas de adaptación y mitigación al cambio climático.

Ahora bien, por parte del PRI se presentó, a través del presidente Enrique Peña Nieto, el 12 de agosto de 2013, la iniciativa de decreto por el que se reforman los artículos 27 y 28 de la Constitución Política de los Estados Unidos Mexicanos, ante la Comisión Permanente del Congreso de la Unión, para ser remitida a la Cámara de Senadores. Dentro de ésta cabe resaltar el cambio en la forma en que se permitía la exploración y explotación, cuya novedad eran los contratos de utilidad compartida; por otro lado, estaba la participación de particulares en la generación de energía eléctrica.

Por último, el PRD hizo lo propio el 19 de agosto de 2013. Esta iniciativa, a diferencia de las dos anteriores, no proponía la apertura del sector energético a la inversión privada, sino el fortalecimiento de la CFE y de Pemex. Convertir a la Comisión Nacional de Hidrocarburos y la Comisión Reguladora de Eenergía en organismos públicos descentralizados, de esta manera adquirirían mayor fuerza, además de crear el Fondo de Excedentes Petroleros.

Las tres iniciativas sirvieron de base para que el Congreso discutiera los pros y los contras de cada una y adecuar lo que se considerara conveniente. Es así como el 20 de diciembre de 2013 se publicó el decreto por el cual se reformaban los artículos 25, 27 y 28 y se adicionaron diversas disposiciones de la Constitución Política de los Estados Unidos Mexicanos en materia de energía, además de incluir 21 artículos transitorios, con entrada en vigor al día siguiente de su publicación De lo cual se destaca lo siguiente: 


\begin{tabular}{|c|c|}
\hline Artículo 25 & $\begin{array}{l}\text { Se reforma el párrafo cuarto en el cual se introduce el concepto "empresas } \\
\text { productivas del Estado", además de redefinir el alcance del sector energético } \\
\text { como área estratégica de la economía. } \\
\text { Es importante destacar que la ley establecerá las normas relativas al "régi- } \\
\text { men de remuneraciones de su personal, para garantizar su eficacia, eficien- } \\
\text { cia, honestidad, productividad, transparencia y rendición de cuentas, con } \\
\text { base en las mejores prácticas, y determinará las demás actividades que po- } \\
\text { drán realizar" (DOF 20-12-2013). } \\
\text { Párrafo sexto. Incorpora el concepto de sustentabilidad bajo el cual se apoya- } \\
\text { rá e impulsará a las empresas de los sectores social y privado de la economía. } \\
\text { Párrafo octavo. Incorpora la referencia al desarrollo industrial sustentable } \\
\text { como parte de una política nacional. }\end{array}$ \\
\hline Artíc & $\begin{array}{l}\text { Se reforma el párrafo sexto "se elimina la prohibición de celebrar contratos } \\
\text { con particulares en materia de hidrocarburos. } \\
\text { Se reduce el monopolio estatal a las siguientes actividades del sector eléc- } \\
\text { trico: a. planeación y el control del sistema eléctrico nacional; b. servicio } \\
\text { público de transmisión y distribución de energía eléctrica. } \\
\text { En esas actividades reservadas a la nación se prohíbe otorgar concesiones, } \\
\text { pero se permite celebrar contratos con particulares. } \\
\text { Se adiciona el párrafo séptimo recorriéndose los subsecuentes. Por el cual se } \\
\text { reitera la prohibición de otorgar concesiones exploración y extracción del } \\
\text { petróleo y demás hidrocarburos, pero se autoriza la celebración de contratos } \\
\text { para que los particulares lleven a cabo esas actividades. } \\
\text { Se introduce el mecanismo de la asignación para que empresas productivas } \\
\text { del Estado lleven a cabo por sí o a través de empresas privadas las actividades } \\
\text { reservadas a la nación en materia de hidrocarburos" (González 2017, 99). }\end{array}$ \\
\hline Artíc & $\begin{array}{l}\text { Se reforma párrafo cuarto. En cuanto al "sector eléctrico se reduce el alcance } \\
\text { del monopolio estatal a las actividades de planeación el control del sistema } \\
\text { eléctrico nacional, así como el servicio público de transmisión y distribución } \\
\text { de energía eléctrica... } \\
\text { Con relación al sector hidrocarburos, se reduce el monopolio estatal de las } \\
\text { actividades de exploración y extracción del petróleo y demás carburos de } \\
\text { hidrógeno" (González 2017, 102). } \\
\text { Párrafo sexto. Crea el Fondo Mexicano del Petróleo para la Estabilización y } \\
\text { el Desarrollo. } \\
\text { Se adiciona el párrafo octavo recorriéndose los subsecuentes. A través de este } \\
\text { se establece que el Ejecutivo contará con los órganos reguladores coordina- } \\
\text { dos en materia energética: Comisión Nacional de Hidrocarburos y Comisión } \\
\text { Reguladora de Energía. }\end{array}$ \\
\hline $\begin{array}{l}\text { Transitorio } \\
\text { cuarto }\end{array}$ & $\begin{array}{l}\text { Establece que el Congreso de la Unión tiene ciento veinte días naturales } \\
\text { siguientes a la entrada en vigor del decreto para realizar las modificaciones } \\
\text { necesarias al marco jurídico y así hacer efectivas las disposiciones estableci- } \\
\text { das en éste. }\end{array}$ \\
\hline
\end{tabular}

FUENTE: Elaboración propia a partir de González (2017, 97-104) 
El 11 de agosto de 2014 se publicó en el DOF la legislación secundaria correspondiente a la reforma energética, en donde se crearon nueve leyes y se reformaron doce.

Nuevas leyes:

1. Ley de Hidrocarburos.

2. Ley de la Industria Eléctrica.

3. Ley de Energía Geotérmica.

4. Ley de los Órganos Reguladores Coordinados en Materia Energética.

5. Ley de la Agencia Nacional de Seguridad Industrial y de Protección al Medio Ambiente del Sector Hidrocarburos.

6. Ley de Petróleos Mexicanos.

7. Ley de la Comisión Federal de Electricidad.

8. Ley de Ingresos sobre Hidrocarburos.

9. Ley del Fondo Mexicano del Petróleo para la Estabilización y el Desarrollo.

Leyes reformadas:

1. Ley de Aguas Nacionales.

2. Ley Orgánica de la Administración Pública Federal.

3. Ley de Inversión Extranjera.

4. Ley Minera.

5. Ley de Asociaciones Público Privadas.

6. Ley Federal de las Entidades Paraestatales.

7. Ley de Adquisiciones, Arrendamientos y Servicios del Sector Público.

8. Ley de Obras Públicas y Servicios Relacionados con las Mismas.

9. Ley Federal de Derechos.

10. Ley de Coordinación Fiscal.

11. Ley Federal de Presupuesto y Responsabilidad Hacendaria.

12. Ley General de Deuda Pública.

Con lo hasta ahora analizado nos podemos dar cuenta del enfoque que se buscó darle a la reforma energética; es decir, hacer de Pemex y de la $\mathrm{CFE}$, empresas competitivas en sus respectivos mercados frente a par- 
ticulares, y de esta manera operar con mayores recursos económicos y ser redituables para el Estado.

\section{EJES EN MATERIA DE CONTROL SOBRE LAS EMPRESAS PRODUCTIVAS DEL ESTADO CON BASE EN LA REFORMA ENERGÉTICA DE 2013}

Como hemos ido analizando en el presente trabajo, la reforma energética ha significado una restructuración radical para Pemex y la CFE debido al cambio de naturaleza jurídica que sufrió; es decir, de ser organismos públicos descentralizados ahora son empresas productivas del Estado (tema que se abordará con mayor detenimiento más adelante). Lo anterior supone un enfoque de gobierno corporativo, capaz de generar valor económico. De aquí se desprendan nuevas obligaciones.

Es importante conocer lo que implica el gobierno corporativo, con respecto a éste es que se establecieron ejes en materia de control y transparencia. Por lo que enunciaremos dos definiciones que nos ayudarán a entender mejor el alcance de la nueva forma de organización de Pemex y de la CFE.

La estructura organizacional de la Empresa, la determinará su Consejo de Administración, salvo los principios básicos establecidos por la propia ley, atendiendo a su autonomía operativa y de gestión, así como a los siguientes principios: optimizar recursos (humanos, financieros y materiales), simplificar los procesos, actuar con eficiencia y transparencia, así como adoptar todas las medidas que resulten de las mejores prácticas corporativas y empresariales (Miranda 2015, 82).

El gobierno corporativo es el marco de normas y prácticas, que se refieren a las estructuras y procesos para la dirección de las compañías, por el cual un consejo de administración asegura la rendición de cuentas, la equidad y la transparencia en la relación de una empresa con sus todas las partes interesadas (la junta directiva, los accionistas, clientes, empleados, gobierno y la comunidad) (Bolsa Mexicana de Valores, gobierno corporativo).

De las definiciones anteriores podemos destacar la transparencia y la rendición de cuentas. Recordemos que estos términos son herramientas 
del control gubernamental, sin dejar a un lado la vigilancia y la auditoría. Dada su importancia y trascendencia es que se consideraron parte de los objetivos de la reforma.

En la iniciativa de reforma constitucional se establece como eje estratégico la transparencia, con la cual se pretende "garantizar a los mexicanos el adecuado acceso a la información sobre la administración del patrimonio energético nacional" (Proyecto de iniciativa de reforma a los artículos 27 y 28 de la CPEUM del Ejecutivo Federal 2013, 1).

El 30 de abril de 2014, el presidente Enrique Peña Nieto envió el paquete de legislación secundaria en materia energética, dentro del cual se encuentra la iniciativa de decreto por el que se expiden la Ley de Petróleos Mexicanos y la Ley de la Comisión Federal de Electricidad, se reforman y derogan diversas disposiciones de la Ley Federal de Entidades Paraestatales, la Ley de Adquisiciones, Arrendamientos y Servicios del Sector Público y la Ley de Obras Públicas y Servicios Relacionados con las Mismas, en la cual someten a consideración del Congreso de la Unión las nuevas leyes de Pemex y CFE "siguiendo los principios, reglas y directrices que la propia Constitución estableció para garantizar su autonomía, eficiencia y transparencia" (Senado de la República 2014, 2).

Tomando en consideración los siguientes ejes de cambio:

— Rediseño integral de los esquemas de vigilancia y auditoría, y

- Nuevos mecanismos de transparencia y rendición de cuentas (Senado de la República 2014, 2 y 3).

Como parte de los objetivos:

- Garantizar estándares internacionales de eficiencia, calidad y confiabilidad de suministro, transparencia y rendición de cuentas.

- Combatir de manera efectiva la corrupción en el sector energético (Reforma energética 2013, 3).

Diversos son los estudios que se han hecho en la materia; dentro de éstos destaca el realizado por Emilio Lozoya $(2014,193)$ ex director general de Pemex de 2012 a 2016, quien pronuncia lo siguiente: 
La reforma aumentará la transparencia y la rendición de cuentas en la industria y en Petróleos Mexicanos por tres caminos:

- Las nuevas facultades de los órganos regulatorios, en particular la CNH (que implican que Pemex deje de ser juez y parte al establecer sus prioridades de inversión) harán más transparente el proceso de priorización de proyectos de Pemex.

- En segundo lugar, la reforma establece que los procesos de licitación y asignación de bloques, lo mismo que los pagos de diverso tipo que se hagan al amparo de los contratos con empresas privadas, sean públicos.

- En tercer lugar, la participación de Pemex en asociación con empresas líderes a nivel mundial implicará mayor transparencia y divulgación de información.

A raíz de la reforma energética a nivel constitucional de los artículos 25, 27 y 28, se emitió en febrero de 2014 la Estrategia Nacional de Energía, instrumento en el cual se esclarece el funcionamiento y rumbo que ha de tomar el sector energético basado en sus diferentes sectores y actores. Para ello toma en cuenta los objetivos de la reforma, como es "garantizar estándares internacionales de eficiencia, transparencia y rendición de cuentas" (Estrategia Nacional de Energía, Gobierno de México 2014, 8), el cual busca dar seguridad en cuanto a las actuaciones de la CFE y Pemex con los inversionistas, y a su vez con la sociedad.

Los ejes y objetivos planteados por la reforma energética pretenden evitar la corrupción, brindar mayor transparencia en las acciones de las empresas productivas del Estado para con los ciudadanos, y de esta manera generar confianza y seguridad. Con posterioridad se explica cómo es que éstos se materializan.

\section{Naturaleza jurídica de Pemex y GFE}

Con la reforma constitucional en materia energética, ahora Pemex y la CFE tienen una nueva naturaleza jurídica, ya que anteriormente eran organismos públicos descentralizados. Recordemos que el artículo 90 constitucional señala que la administración pública federal será centralizada y paraestatal; del mismo modo se establece en la Ley Orgánica de la Administración Pública Federal esta forma de organización del Poder Ejecutivo. 
"La centralización es una forma organizacional que se emplea tanto en el ámbito político como en la esfera administrativa del Estado, consistente en reunir en un punto de convergencia, configurado como un ente central, la toma de decisiones del poder público" (Fernández 2016, 82). Es así que dentro de la administración pública centralizada encontramos a las secretarías de Estado (actualmente hay 19).

La administración paraestatal se compone de la siguiente forma:

Está integrada por el conjunto de instituciones, organismos, empresas de economía mixta, patrimonios públicos, que por disposición de la ley, colaboran en la realización de los fines del Estado, sin formar parte de la administración pública centralizada, con la cual mantienen estrictas relaciones de control y vigilancia a cargo de aquélla, y dividida en sectores para tal efecto (Serra Rojas 2016, 729).

Tanto la ley de Pemex como la ley de la CFE establecen que ambas son empresas productivas del Estado de propiedad exclusiva del gobierno federal, con personalidad jurídica y patrimonio propios, y gozarán de autonomía técnica, operativa y de gestión. Esto conlleva a una nueva naturaleza jurídica dentro de la administración pública en México, pues no se contemplaba para ninguna otra entidad esta forma de organización.

$\mathrm{El}$ artículo transitorio vigésimo del decreto publicado en el $D O F$ el 20 de diciembre de 2013 señaló cuáles serían los aspectos que entrañaban la nueva naturaleza, y que por tanto tenían que regularse en la legislación secundaria respecto de las empresas productivas del Estado:

Vigésimo. Dentro del plazo previsto en el transitorio cuarto de este Decreto, el Congreso de la Unión realizará las adecuaciones al marco jurídico para regular a las empresas productivas del Estado, y establecerá al menos que:

I. Su objeto sea la creación de valor económico e incrementar los ingresos de la nación, con sentido de equidad y responsabilidad social y ambiental.

II. Cuenten con autonomía presupuestal y estén sujetas sólo al balance financiero y al techo de servicios personales que, a propuesta de la Secretaría del ramo en materia de Hacienda, apruebe el Congreso de la Unión. Su régimen de remuneraciones será distinto del previsto en el artículo 127 de esta Constitución.

III. Su organización, administración y estructura corporativa sean acordes con las mejores prácticas a nivel internacional, asegurando su autonomía técnica y de gestión, así como un régimen especial de contratación para la 
obtención de los mejores resultados de sus actividades, de forma que sus órganos de gobierno cuenten con las facultades necesarias para determinar su arreglo institucional.

IV. Sus órganos de gobierno se ajusten a lo que disponga la ley y sus directores sean nombrados y removidos libremente por el titular del Ejecutivo federal o, en su caso, removidos por el Consejo de Administración. Para el caso de empresas productivas del Estado que realicen las actividades de exploración y extracción de petróleo y demás hidrocarburos sólidos, líquidos o gaseosos en términos de lo previsto por el párrafo séptimo del artículo 27 de esta Constitución, la ley deberá establecer, entre otras disposiciones, que su Consejo de Administración se conforme de la siguiente manera: cinco consejeros del gobierno federal, incluyendo el secretario del ramo en materia de energía quien lo presidirá y tendrá voto de calidad, y cinco consejeros independientes.

V. Se coordinen con el Ejecutivo federal, a través de la dependencia competente, con objeto de que sus operaciones de financiamiento no conduzcan a un incremento en el costo de financiamiento del resto del sector público o bien, contribuyan a reducir las fuentes de financiamiento del mismo.

VI. Cuenten, en términos de lo establecido en las leyes correspondientes, con un régimen especial en materia de adquisiciones, arrendamientos, servicios y obras públicas, presupuestaria, deuda pública, responsabilidades administrativas y demás que se requieran para la eficaz realización de su objeto, de forma que les permita competir con eficacia en la industria o actividad de que se trate.

El objeto de convertir a Pemex y a la CFE en empresas productivas del Estado radicó en la necesidad de crear una forma de organización dentro de entidades que forman parte de la administración pública, que tuvieran una mayor independencia que le permitiera ejercer sus funciones con el objetivo de crear mayores ingresos, debido a que anteriormente estaban reportando grandes pérdidas, sobre todo en el caso de Pemex, lo que significaba un decremento en las finanzas públicas y el desarrollo económico de la nación.

La nueva estructuración pugnó por una forma de organización corporativa, es decir, que observa ciertos principios de la Constitución y operación de una persona moral de carácter privado; tienen un director general, un consejo de administración y comités que apoyan al Consejo en el ejercicio de sus funciones. 
Otro de los objetivos de optar por esta naturaleza fue la de incorporar las mejores prácticas de gobierno corporativo, con mayor transparencia en el ejercicio de sus funciones, responsabilidad y rendición de cuentas. De esta forma, se transformaban las funciones tanto de Pemex como de la CFE para evitar la opacidad y contribuir al fortalecimiento de las instituciones bajo un amplio espectro democrático.

Conocemos cuál es la naturaleza de Pemex y de la CFE, y en qué consiste la misma, pero quedó un tema pendiente, relativo a en dónde se encuadran las empresas productivas del Estado. Resulta bastante obvio que no forman parte de la administración pública centralizada, pero queda en duda si podemos incluirlas dentro de la administración paraestatal. Esta cuestión se presenta debido a que el artículo 3o. de la Ley Federal de Entidades Paraestatales señala en su último párrafo:

Las empresas productivas del Estado y sus respectivas empresas productivas subsidiarias, la Procuraduría Agraria, la Procuraduría Federal del Consumidor, la Agencia de Noticias del Estado Mexicano y el Sistema Público de Radiodifusión del Estado Mexicano, atendiendo a sus objetivos y a la naturaleza de sus funciones, quedan excluidas de la observancia del presente ordenamiento.

Por tanto, este ordenamiento las excluye de ser reguladas como entidades paraestatales, ya que conocemos que ambas empresas productivas cuentan con su legislación especial aplicable. Sin embargo, existen criterios judiciales (tesis aislada, segunda sala, LXXX/2018), que señalan que estas empresas son una nueva categoría de entidades paraestatales con un régimen especial y diferenciado, basado en principios de gobierno corporativo, que ya hemos analizado.

Ambos criterios coinciden en que la finalidad de esta naturaleza es permitir a las empresas productivas, competir con flexibilidad y autonomía en el sector energético a fin de crear un valor económico para la nación.

El artículo 2o. de la Ley de Pemex y el artículo 2o. de la Ley de la CFE señalan que ambas empresas son de propiedad exclusiva del gobierno federal. Por su parte, la Ley Orgánica de la Administración Pública Federal, en su artículo 1o. establece que las empresas de participación estatal componen a la administración pública paraestatal; es así, que refrendando lo 
establecido en el criterio jurisprudencial, podemos determinar que ambas empresas productivas forman parte de la administración paraestatal.

\section{CONTROL DE LAS EMPRESAS PRODUCTIVAS DEL ESTADO}

La nueva naturaleza que la reforma energética dio a Pemex y a la CFE como empresas productivas del Estado modificó la forma en que se realiza su control, el cual es distinto al que se ejerce en los demás integrantes de la administración pública en vista del nuevo gobierno corporativo.

Para estudiar los cambios al respecto, analizaremos la Ley de Petróleos Mexicanos y la Ley de la Comisión Federal de Electricidad; en cada una se establece la estructura y las normas que se encargarán de su regulación. Se hace la aclaración de que las dos leyes son similares, por no decir idénticas; por tanto, el análisis que se presenta en los siguientes párrafos hace referencia al contenido de ambos instrumentos jurídicos.

El artículo 1o. de ambas leyes señala que su objeto es regular, entre otros aspectos, el control, la evaluación y la rendición de cuentas de las empresas productivas del Estado. De esta forma, en el título tercero de ambas leyes se establece lo respectivo a su vigilancia y auditoría; en este apartado se consideran algunas de las disposiciones más importantes en cuanto al control, que contribuyen a la supuesta rendición de cuentas y transparencia que propició la reforma. La ley establece que ambas empresas productivas contarán con un Comité de Auditoría, una Auditoría Interna y una Auditoría Externa, que tienen a su cargo la función de vigilancia y auditoría.

El Comité de Auditoría es uno de los comités que forma parte del Consejo de Administración, junto con el de Recursos Humanos y Remuneraciones, Estrategia e Inversiones y Adquisiciones, Arrendamientos, Obras y Servicios. La Ley señala que el Consejo de Administración podrá además establecer los demás comités que requiera. Por lo que se refiere al Comité de Auditoría, éste tendrá a su cargo la organización, planeación y emisión de directrices en cuanto al control y vigilancia interna de las empresas productiva del Estado, respectivamente; estas actividades serán ejecutadas por la auditoría interna.

Dentro de estas actividades, el Comité será el responsable de la verificación del cumplimiento de las metas, objetivos, planes y programas, que miden el desempeño de las empresas productivas; además, tendrá a su cargo la vigilancia de la información contable y financiera. El Comité 
será el encargado de aprobar el programa anual de auditoría interna; de la misma forma, podrá requerir las investigaciones y práctica de auditorías cuando lo estime necesario.

Es así que este Comité es el encargado del diseño y evaluación de la auditoría interna. El artículo 51 de la Ley de Petróleos Mexicanos y el artículo 50 de la Ley de la Comisión Federal de Electricidad, respectivamente, enumeran todas las funciones de forma específica a cargo del Comité, que en ambos casos tienen las mismas funciones. A continuación se abordan algunas de ellas que representan inconvenientes, y cabe hacer algunas críticas al respecto.

Una de las funciones del Comité es proponer al titular de la Auditoría Interna y evaluar su desempeño; la designación estará a cargo del Consejo de Administración. Posteriormente, también se establece que tendrá a su cargo la contratación del auditor externo. Más adelante analizaremos cómo estos puntos pueden representar un menoscabo en materia de rendición de cuentas. La auditoría interna tiene a su cargo la ejecución de las normas y controles establecidos por el Comité de Auditoría, así como poner en marcha todas las acciones solicitadas por éste.

Posteriormente, en ambas leyes se reitera que el Consejo de Administración designa al titular de la auditoría interna a propuesta del Comité de Auditoría. Señala que el titular de la auditoría interna puede ser removido libremente por el Comité de Auditoría. Es necesario recalcar que esto representa un peligro para el control interno de las empresas productivas, pues no se establece ningún tipo de seguridad en cuanto al nombramiento del auditor interno, que tiene funciones de gran peso en torno al control y auditoría.

Las funciones del auditor interno se contemplan en el artículo 54 de la Ley de Pemex, y en el artículo 53 de la Ley de la CFE. Analizando cada una de ellas, se puede concluir que se contemplan una serie de medidas adecuadas y acertadas para poder evaluar el desempeño de las actividades y acciones de las empresas productivas. Si las observamos a la luz de la teoría sobre transparencia, sus requerimientos se ven colmados.

Estas funciones se pueden resumir de la siguiente forma:

- Revisar de forma material el cumplimiento de las políticas y disposiciones jurídicas aplicables que propician el adecuado funcionamiento de la institución. 
- Tiene la facultad de verificar los sistemas informáticos que contengan la información contable y operacional de la entidad.

- Pueden hacer una evaluación de la calidad, suficiencia y oportunidad de la información de manera que sea confiable y adecuada para que se tomen decisiones de forma correcta y oportuna.

- Verifica el desempeño de funciones de acuerdo con la distribución de competencias.

- Será el encargado de proporcionar al Comité de Auditoría la información respecto de irregularidades detectadas; si éstas llegaran a constituir responsabilidades se deberán iniciar los procedimientos correspondientes. Si detecta responsabilidades administrativas deberá ponerlas a disposición de la Unidad de Responsabilidades.

- De toda su gestión deberá informar por lo menos de forma semestral al Comité de Auditoría.

En cuanto a la auditoría externa, será designada por el Consejo de Administración a propuesta del Comité de Auditoría.

Finalmente, en ambos instrumentos se dispone que la Auditoría Superior de la Federación sea la competente para fiscalizar las empresas productivas del Estado, puesto que se encarga del control externo, y tiene a su cargo la fiscalización superior, función mediante la cual revisa la cuenta pública, documento donde se refleja el ejercicio del presupuesto de egresos. La actividad de Pemex y de la CFE no puede escapar de este tipo de control, dado que ambas empresas se encuentran dentro de la administración pública federal y reciben recursos a través del presupuesto de egresos. Para que la Auditoría Superior pueda llevar a cabo la fiscalización de las empresas productivas, deberá tener en cuenta su naturaleza especial, así como la legislación que las regula y el decreto del 20 de diciembre de 2013, que dio paso a la reforma energética.

Dentro de esta serie de disposiciones que norman la nueva naturaleza y funciones de las empresas productivas existen diversos aspectos que se tienen que revisar de forma cuidadosa. En primer lugar, al conformar a Pemex y la CFE con una nueva naturaleza, en la búsqueda de un gobierno corporativo dentro de ellas, se modifican sus formas de control interno, las cuales son distintas en comparación con los demás entes de la administración pública federal. En un principio podríamos decir que estas mo- 
dificaciones fortalecen y ejercen un mayor control respecto de su actividad, pues además de su control interno se dotan de otros mecanismos que abonan en la rendición de cuentas y transparencia, como las auditorías interna y externa, previas a la auditoría superior. Sin embargo, la reforma en este aspecto deja mucho que desear respecto a la forma en que se diseñaron los mecanismos de control. Las modificaciones en estos temas son un intento de dar una apariencia de supuesto control que en realidad no existe, lo único que se presenta es la construcción de una burocracia mayormente articulada, donde se han acomodado todas las piezas para que estéticamente sean observadas como medidas más fuertes y robustecidas de control, pero que finalmente no tienen un diseño con verdadera voluntad política de trasparencia, fiscalización y rendición de cuentas.

La auditoría y la vigilancia se presentan en tres momentos distintos. El Comité de Auditoría, que es parte del Consejo de Administración, es el encargado del diseño de los programas y políticas de auditoría; además, funge como intermediario entre el Consejo y las auditorías interna y externa. Este Comité es el encargado de proporcionar los instrumentos necesarios al auditor interno, que a su vez es elegido por el mismo Comité; igualmente, la ley establece que también puede removerlo de forma libre. Esta última disposición resulta arbitraria y dudosa, puesto que la Ley no exige algún requerimiento o motivos por los cuales pueda ser removido el titular de la auditoría interna. Se debió establecer en la ley secundaria cuáles serían los supuestos en los que se puede solicitar su remoción; la Ley literalmente señala que el titular podrá ser removido "libremente", dejando un sinfín de posibilidades por las cuales se pueda quitar al titular.

Así, el Comité de Auditoría se encarga de proponer a los titulares interno y externo, y evalúa el desempeño de los mismos; además, es el conducto entre éstos y el Consejo de Administración. Debió establecerse un diseño distinto en la designación de ambos tipos de auditoría, pues finalmente todas las decisiones y facultades se concentran en el Comité de Auditoría y decide sobre lo que deberá auditarse por ambos, la información que considerará para sus informes, así como la evaluación respectiva de su trabajo. A pesar de que el Comité se conforma por tres consejeros independientes, finalmente forma parte del Consejo de Administración; de ahí que debieron establecerse mayores candados para la operación y designación de las auditorías interna y externa. 
La auditoría interna cuenta con distintas funciones, que son favorables para la adecuada evaluación de la entidad, pero la información resultado de sus trabajos es filtrada por el Comité de Auditoría; de la misma manera, la información que proporcione la auditoría externa contará con dicho filtro a través del Comité. En consecuencia, a pesar de existir diversas auditorías, todas quedan a consideración del Comité, concentrando un número importante de facultades en este órgano, lo que podría atentar contra el control imparcial y eficiente.

Debió establecerse una estructura diferente en la que se distribuyeran de mejor forma las facultades en cuanto a la auditoría de la entidad, donde se presentaran evaluaciones independientes que permitieran la adecuada evaluación y vigilancia, que finalmente se refleja en información valiosa para poder mejorar el desempeño de las empresas productivas, identificando áreas de riesgo, errores y prácticas corruptas, que en todo momento deben corregirse y en su caso sancionarse, para mejorar la calidad del gobierno corporativo.

En lo que respecta al control interno de las empresas productivas del Estado, éste se ejerce de forma distinta al de los demás entes de la administración pública federal. Recordemos la definición propuesta en el segundo apartado de la investigación; el control interno se puede definir como: aquel que debe realizarse [por] la propia administración; esto es, un órgano especializado encuadrado dentro del Poder Ejecutivo, pero situado jerárquicamente en una posición superior o por lo menos no dependiente orgánica ni funcionalmente de ninguna secretaría, con el propósito de investigar, comprobar y, en su caso, informar, sobre la legalidad, eficacia, objetivos, resultados, etcétera, del gasto público (Mijangos 1996, 967).

La reforma en materia energética rompe el principio expresado en la definición anterior. En México, el control interno se realiza por la Secretaría de la Función Pública (SFP), dependencia del Poder Ejecutivo federal. Se encarga del control de la administración pública, al ser un control interno, se encuentra dentro de la administración, pero no depende orgánica ni funcionalmente de ningún ente al que revisa, con la finalidad de tener un mejor desempeño en sus funciones, y que se desarrollen de forma imparcial.

Las funciones que tiene a su cargo la SFP se encuentran descritas en el artículo 37 de la Ley Orgánica de la Administración Pública Federal. En él se enumeran 29 fracciones, que contienen todas sus facultades en 
cuanto a control interno se refiere. Sus funciones se pueden resumir de la siguiente forma:

... vigila que los servidores públicos federales se apeguen a la legalidad durante el ejercicio de sus funciones, sanciona a los que no lo hacen así; promueve el cumplimiento de los procesos de control y fiscalización del gobierno federal, de disposiciones legales en diversas materias, dirige y determina la política de compras públicas de la Federación, coordina y realiza auditorías sobre el gasto de recursos federales, coordina procesos de desarrollo administrativo, gobierno digital, opera y encabeza el Servicio Profesional de Carrera, coordina la labor de los órganos internos de control en cada dependencia del gobierno federal y evalúa la gestión de las entidades, también a nivel federal (SFP).

Todas las entidades y dependencias de la administración pública federal deberán contar con órganos internos de control (OIC), que están facultados para prevenir, corregir e investigar actos $u$ omisiones que pudieran constituir responsabilidades administrativas. Estos órganos tienen facultades de sanción en caso de faltas no graves, y deberán promover ante el Tribunal Federal de Justicia Administrativa aquellas que pudieran constituir faltas graves. Las faltas no graves se encuentran previstas en los artículos 49 y 50 de la Ley General de Responsabilidades Administrativas. Este tipo de faltas se presentan cuando el servidor actúa de forma contraria a los principios que rigen el servicio público: disciplina, legalidad, objetividad, profesionalismo, entre otros. Por su parte, las faltas graves están previstas en los artículos 52 a 64 de la Ley General de Responsabilidades Administrativas; estas faltas son cohecho, peculado, desvío de recursos públicos, utilización indebida de información, abuso de funciones, actuación bajo conflicto de interés, contrataciones indebidas, enriquecimiento oculto u ocultamiento de conflicto de interés, tráfico de influencias, encubrimiento, desacato y obstrucción de la justicia.

Estas funciones se adecuaron en razón de la reforma anticorrupción de 2015.

Los OIC cuentan con una estructura y facultades amplias, y se conforman de la siguiente manera:

— Un área de responsabilidades.

- Un área de quejas.

— Un área de auditoría interna. 
— Un área de auditoría para desarrollo y mejora de la gestión pública.

Entre las funciones más importantes de los OIC se encuentran las siguientes:

- Verificar el cumplimiento de las obligaciones a cargo de los servidores públicos, que se apeguen a los requerimientos legales para el desempeño y gestión gubernamental de forma adecuada.

- Se encargan de la revisión de los recursos públicos en cuanto a su ingreso, administración y aplicación.

- Reciben las denuncias por hechos que pudieran constituir responsabilidades administrativas.

- Pueden ordenar y realizar la práctica de auditorías y revisiones para evaluar el desempeño y la gestión de las entidades de la administración pública.

- Derivado de las funciones descritas, que pueden sustanciar los procedimientos de responsabilidades administrativas e imponer sanciones cuando se trate de faltas no graves. En el caso de faltas administrativas graves, deberá remitir los procedimientos ante el TFJA, o ante la Fiscalía Especializada en Combate a la Corrupción cuando los hechos pudieran ser constitutivos de delitos.

Es así que el sistema de control interno de la administración pública tiene la función de evaluar y revisar la gestión y desempeño de las acciones de gobierno, con la finalidad de poder mejorar, corregir y en su caso sancionar actos contarios a las disposiciones legales que rigen el actuar de las instituciones. Todas estas acciones abonan a la rendición de cuentas, estudiada en el apartado teórico de la investigación.

La reforma anticorrupción de 2015 estableció que ningún ente de la administración pública federal podía estar fuera del control interno, es así, que incluso se determinó que los órganos que gozan de autonomía constitucional también tienen que contar con un OIC que ejerza un control interno, además de estar sujetos al control externo de la ASF.

Sin embargo, la reforma energética no contempla el control interno para Pemex ni para la CFE en la forma que se desarrolla generalmente en los entes que integran a la administración pública federal. Dentro de las empresas productivas no existe un control por parte de SFP a través de 
un OIC. La intervención de la SFP en ambas empresas productivas del Estado es a través de la Unidad de Responsabilidades, dado el régimen especial del que gozan ambas empresas productivas, la cual tiene funciones limitadas en comparación con los OIC presentes en las dependencias de la administración pública. La Ley señala que esta Unidad será la encargada de la aplicación de la Ley Federal de Responsabilidades Administrativas de los Servidores Públicos, pero exclusivamente en dos supuestos:

I. Recibir y dar atención a quejas y denuncias y realizar investigaciones con motivo de las mismas, y

II. Tramitar los procedimientos de responsabilidad administrativa e imponer las sanciones respectivas, en términos de las leyes aplicables.

La Unidad no tiene competencia en materia de control interno y auditoría, debido a que la auditoría se desempeña por los órganos que faculta la ley de forma especial; por ejemplo, el control interno está a cargo del Consejo de Administración de las empresas productivas. Como resultado, toda la amplia gama de funciones que tienen los OIC en cualquier dependencia de la administración pública no son ejercidas de la misma forma dentro de las empresas del sector energético, pues quedan totalmente limitadas y reducidas a las acciones a cargo de las unidades de responsabilidad, cuestión que representa una merma para el desarrollo del control interno por parte de la SFP en lo que respecta al sector energético.

La Ley establece que el Consejo de Administración tendrá la facultad de emitir, a propuesta del Comité de Auditoría, los lineamientos de control interno. También señala que el mismo Consejo tendrá a su cargo la evaluación y seguimiento del control interno, esta función también la desempeña la auditoría.

Se puede observar que el control ejercido dentro de las empresas productivas del Estado se encuentra concentrado en los consejos de administración. Para resumir las funciones en materia de control interno dentro de las empresas productivas del Estado, podemos observar el siguiente esquema: 


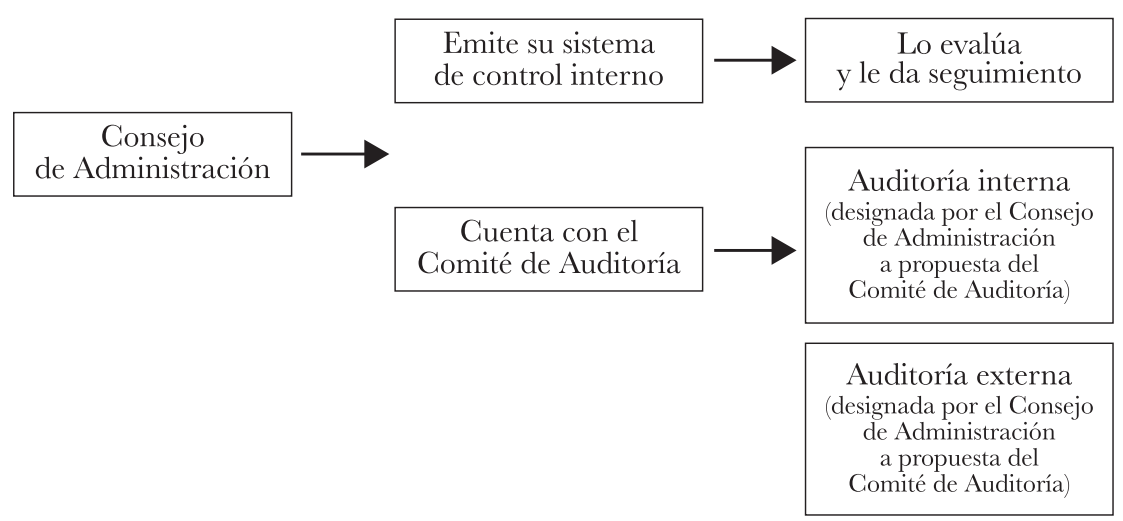

FUENTE: Elaboración propia.

En vista del nuevo gobierno corporativo en las empresas productivas, se han concentrado muchas funciones en sus consejos administrativos, en razón de que se equipara su organización y forma de gobierno al de una empresa privada; sin embargo, esto no puede resultar del todo favorable para una entidad que se encuentra dentro de la administración pública y forma parte de la estructura del Estado, a pesar de formarse por medio de una estructura que nace en el ámbito privado.

En apartados anteriores analizamos que dentro de los principales objetivos de la reforma se encontraban una mejora en la rendición de cuentas y una mayor transparencia; es por eso que se implementaron distintas formas de auditoría, sumadas al control interno dentro de las empresas productivas del Estado; no obstante que existen distintos medios de control, su efectividad puede verse amenazada, en vista de que finalmente toda la información se controla por medio del consejo de administración, en un solo órgano se concentran las funciones, representando sin duda una brecha para que se presenten casos de corrupción y manipulación en el manejo de los datos e información.

Dentro de ambas leyes se contempla un apartado denominado "trasparencia y rendición de cuentas", en donde se establecen una serie de medidas respecto de la divulgación de información que permita conocer la situación de la empresa en materia financiera, administrativa, operacio- 
nal, económica y jurídica. La información debe ser puesta a disposición del público en general.

De la misma forma, se deberá cumplir con las obligaciones que se prevean en la Ley Federal de Transparencia y Acceso a la Información Pública Gubernamental. Por último, se establece la obligación de presentar a más tardar en abril de cada año, un informe al Ejecutivo federal y al Congreso de la Unión que contenga lo siguiente:

I. Un reporte del director general sobre la marcha de Petróleos Mexicanos, sus empresas productivas subsidiarias y empresas filiales y, en su caso, sobre los principales proyectos existentes. Dicho reporte deberá realizarse por línea o rama de negocios, además de emplear indicadores o parámetros usuales a nivel internacional para la correcta y puntual medición de los resultados y estar vinculado a los objetivos y metas que se hayan fijado en el Plan de Negocios;

II. La explicación y declaración de las principales políticas y criterios contables y de información seguidos en la preparación de la información financiera;

III. Los estados que muestren la situación financiera de Petróleos Mexicanos durante y a la fecha de cierre del ejercicio, sus cambios y resultados, así como la demás información que sea necesaria para completar o aclarar los datos suministrados con dichos estados;

IV. Un reporte sobre el ejercicio de su presupuesto, en el que se incluyan las desviaciones en montos, tiempo y alcance de ejecución de los contratos que se lleven a cabo, y

V. La evaluación del Consejo de Administración sobre la ejecución de los programas anuales de Petróleos Mexicanos (artículo 113, Ley de Pemex).

Esta disposición constituye un elemento importante en materia de control, debido a que las empresas productivas tienen que informar y rendir cuentas no únicamente al poder Ejecutivo, pues se encuentran dentro de su estructura, sino que además se señala la obligación de reportar sus actos ante el Congreso de la Unión, que recordemos cuenta también con el control externo ejercido a través de la ASF.

El inconveniente se presenta debido a que las leyes no establecen qué sucederá si se detectan irregularidades en alguno de estos informes; el requisito parece satisfecho con la simple entrega de la información. Esta medida representa logros en materia de transparencia, pero no es sufi- 
ciente si se analiza desde el punto de la rendición de cuentas; en todo caso se está propiciando la vertiente de una rendición de cuentas blanda, al no establecer mecanismos de sanción en caso de posibles irregularidades.

Por último, para reforzar todos los mecanismos anteriores se agregó una forma adicional de control y transparencia. Se estableció tanto para Pemex como para la CFE una evaluación a cargo de un comisario independiente, que tiene que elaborar un informe que se presenta a la Cámara de Diputados y al Ejecutivo federal a más tardar el 30 de junio de cada año. El comisario será designado por el Pleno de la Cámara de Diputados a propuesta del Instituto Mexicano de Ejecutivos de Finanzas previa solicitud del Ejecutivo federal.

Este informe es una evaluación que incluye un análisis sobre la situación operativa, programática y financiera de las empresas productivas del Estado; derivado de su trabajo debe elaborar recomendaciones para el Consejo de Administración y el director general de las empresas productivas, respectivamente.

Esta disposición representa una última forma de control externo. El problema sigue siendo el mismo: que no se considera ningún tipo de procedimiento ante la detección de irregularidades; asimismo, los requisitos se ven colmados con la simple entrega de información; además, el informe que se elabore será con base en la información que le proporcione el director general de cada una de las empresas, no se establecieron mecanismos para que el comisario pudiera allegarse de la información de forma directa o por medio de otros conductos, con el fin de que existiera una pluralidad de datos a partir de diversas fuentes.

En suma, el consejo de administración de ambas empresas productivas cuenta con todas las facultades, y tiene a su disposición todas las herramientas de control, tanto en temas de transparencia como en rendición de cuentas; de igual manera, se encarga de filtrar toda la información que sale al exterior; por ejemplo, la que otorga al comisario independiente.

Estos hechos pueden representar un peligro para el debido control de las empresas productivas del Estado, pues no existe un adecuado flujo de la información ni una serie de facultades compartidas en materia de transparencia y rendición de cuentas donde participen distintos actores que descarguen y distribuyan las funciones para obtener procesos imparciales.

Por otro lado, resta comentar algunos aspectos sobre los órganos reguladores coordinados en materia energética. Estos órganos son la Comi- 
sión Nacional de Hidrocarburos y la Comisión Nacional Reguladora de Energía, ya que cada uno interviene según la materia que le corresponde. El 11 de agosto de 2014 se publicó en el DOF la Ley de los Órganos Reguladores Coordinados en Materia Energética dentro de un paquete de leyes secundarias, que se encargaron de reglamentar la reforma constitucional en materia energética.

Ambos órganos tienen autonomía técnica, operativa y de gestión; en el ejercicio de sus atribuciones deben coordinarse con la Secretaría de Energía (Sener). Dentro de la gama tan amplia de funciones que tienen los órganos reguladores, son de relevancia en materia de transparencia y control para Pemex y la CFE, la posibilidad de otorgar permisos, autorizaciones y emitir demás actos administrativos vinculados con la materia energética en su ramo respectivo.

Otra función relevante consiste en poder solicitar a las empresas productivas la información y documentación necesaria para la revisión de su debido funcionamiento; de la misma forma, podrá hacerlo con los terceros relacionados.

Los órganos reguladores desempeñan ciertas funciones en materia de control y vigilancia de las empresas productivas, puesto que además de poder solicitar datos e información pueden ordenar y realizar visitas de verificación, inspección, o supervisión, con objeto de revisar y evaluar el cumplimiento de las disposiciones jurídicas aplicables que norman el actuar de ambas empresas, así como el cumplimiento de lo dispuesto en los permisos y autorizaciones respecto de los convenios y contratos regulados. También podrán llevar a cabo visitas de inspección cuando así lo ordene la Sener y la Secretaría de Hacienda y Crédito Público (SHCP).

Dentro de la Ley de los órganos reguladores se dispone en el capítulo XII un apartado respecto del combate a la corrupción. En este capítulo se establece que los órganos reguladores deberán contar con mecanismos que permitan la prevención e identificación de actos ilícitos, irregulares o negligentes, y en el caso de su comisión, medidas que permitan subsanar y sancionar estos actos $\mathrm{u}$ omisiones. Estas medidas tienden a establecer un mejor control dentro de los procesos por los que se otorgan permisos y contratos en materia energética.

Con la reforma, ambos órganos reguladores tienen mayores facultades y participación dentro de las distintas actividades ejercidas por las 
empresas productivas de Estado; ahora estos órganos tendrán un papel relevante en la contratación de exploración y extracción de hidrocarburos.

En el caso específico de Pemex, antes de la reforma podía decidir con libertad el otorgamiento de contratos de exploración y extracción con la aprobación de la Sener, pero esta aprobación constituía un mero trámite; por tanto, no estaban debidamente reguladas las decisiones de Pemex, ahora la Comisión Nacional de Hidrocarburos $(\mathrm{CNH})$ tiene una participación efectiva, pues podrán participar en los permisos y autorizaciones de contratación en la materia.

Todo lo concerniente a los contratos de exploración y extracción que celebren será determinado por la Sener conjuntamente con la GNH, que serán las encargadas de los procesos de licitación y asignación de los contratos quitando esta función tradicional y exclusiva a Pemex, además de que la GNH podrá realizar la revisión y verificación de la operación de los mismos.

Derivado del análisis de las funciones de los órganos reguladores, podemos concluir que también cuentan con facultades en materia de control y vigilancia de las empresas productivas del Estado.

A pesar de que se ha construido todo un sistema en el cual participan distintas autoridades e instituciones en el funcionamiento de Pemex y la CFE, como se ha expuesto en los últimos párrafos, no resulta del todo satisfactorio en términos de control y transparencia. Es cierto que se trata de un nuevo modelo en materia energética dentro del Estado mexicano, pero también lo es que la construcción del nuevo sistema de control no resulta favorable, debido a la intervención de múltiples autoridades, que hacen complicado el estudio y la vigilancia de las empresas productivas del Estado, ya que si bien participan en distintos procesos dentro de sus actividades, como la contratación de servicios o licitaciones, no existe un ente que se encargue del control efectivo de auditoría y manejo de recursos públicos.

Actualmente las EPE se encuentran en un esquema de gobernanza híbrida, con un Consejo de Administración con consejeros independientes, pero también con asientos para la Secretaría de Energía (Sener), la Secretaria de Hacienda y Crédito Público (SHCP), la Secretaría de Economía (SE) y la Secretaría de Medio Ambiente y Recursos Naturales (Semarnat). Es decir, una empresa productiva con herencia paraestatal, con poca transparencia a los 
mercados en el manejo de sus finanzas y una fuerte vinculación a la estructura de la SHCP. Ambas EPE continúan siendo valoradas como empresas del Estado, con directores generales nombrados por el partido en el poder, limitando su actuación como directores ejecutivos que deben competir y tomar decisiones de negocios a largo plazo (Olivas 2017, 49).

La cita anterior confirma que es cierto que participan diversas autoridades dentro de las empresas productivas del Estado, las cuales tienen funciones específicas, dentro de distintas actividades, pero que ninguna de ellas llega a homogeneizar un proceso que aporte efectivamente al control y rendición de cuentas.

\section{CONCLUSIONES}

La reforma del 20 de diciembre de 2013 representa un cambio trascendental, que modificó la forma y estructura en que se concebía el sector energético en México. Pemex y la CFE tomaron una nueva naturaleza jurídica como empresas productivas del Estado para poder implementar una forma de gobierno corporativo, que supone una mayor transparencia y rendición de cuentas, pues ambos tópicos fueron ejes de la reforma constitucional; así, se presentó una posible solución al problema de la corrupción.

Se diseñó un nuevo modelo de auditoría y vigilancia dentro de ambas empresas productivas; sin embargo, no cumple con las expectativas y objetivos que se propusieron en la reforma, ya que su control es cerrado y no permite la intervención de distintos actores que hagan más transparentes los procesos de revisión, evaluación y vigilancia.

Existe una gran cantidad de funciones en materia de control que se concentran dentro de los consejos de administración tanto de Pemex como de la CFE, cuestión que representa un peligro, debido a que toda la información resultado del ejercicio de los diversos medios de control finalmente se filtran por el Consejo; esta situación podría generar cierto nivel de opacidad.

Con la participación de los órganos reguladores en la celebración de contratos que pueden llevar a cabo Pemex y la CFE, se ven fortalecidas algunas funciones para evitar la corrupción y generar un mayor control en el desarrollo de los mismos, pero hay que recordar que aún quedan un sinnúmero de funciones que son vigiladas al interior de ambas empresas 
productivas; además, como se destacó a lo largo de la investigación, la intervención de distintas autoridades entraña un sistema complejo, que dificulta los mecanismos de rendición de cuentas y difusión de la información, alejándose de los estándares de transparencia que permitan el fácil acceso al conocimiento de la toma de decisiones dentro de las empresas productivas del Estado, sobre todo las que tengan que ver con el manejo de recursos económicos.

A raíz de la reforma se generaron diversos medios de revisión y vigilancia, como el informe que debe presentar el director de cada una de las empresas productivas al Ejecutivo Federal y el Congreso de la Unión, o el caso de la evaluación a cargo del comisario externo. Todos estos mecanismos sugieren una mayor vigilancia gubernamental del desempeño de las empresas productivas del sector energético; no obstante, sus diseños requieren un mayor esfuerzo, que contengan medidas concretas de identificación, solución y sanción de hechos de corrupción y cualquier otro tipo de actos u omisiones que atenten contra el debido desarrollo del sector energético.

El gobierno corporativo propuesto concentra las decisiones en muy pocos actores, con la finalidad de un mejor desempeño, que incremente los ingresos en el sector, pero este tipo de diseños no pueden adoptarse dentro de entes que formen parte de la administración pública, pues a pesar de contar con tal naturaleza, aun pertenecen al Estado y se encuentran dentro de la estructura gubernamental; por ello, deben incluirse una serie de acciones distribuidas entre diversos actores, que eviten la concentración de funciones y poder, lo que conlleva a una mayor transparencia y adecuado desempeño institucional.

Por un lado, se agregan funciones de vigilancia y auditoría, pero a la vez se desvinculan de ciertos controles tradicionales, como el practicado por la SFP en su modalidad de auditoría interna, que suponía mayor intervención por parte de distintos entes que permitían un mayor flujo de información y, por ende, un control adecuado.

Dentro de los grandes problemas se encuentra la ausencia de sanciones o procedimientos de actuación ante la detección de irregularidades derivada del ejercicio de los medios de control, como el practicado por el comisario externo o el derivado de la evaluación que presenta el director general de cada empresa productiva al Ejecutivo y al Congreso de la 
Unión; en todos los casos, a lo más que puede llegarse es a la emisión de simples recomendaciones.

Posterior a estas formas de revisión, al final del camino queda el control externo practicado por la ASF; pero hay que decir que bajo esta revisión tampoco hay mucho en cuanto a procesos efectivos de sanción. Definitivamente, no se han cumplido las exigencias de una adecuada rendición de cuentas, mucho menos de procesos efectivos de control, pues aún falta mucho por mejorar, ya que si bien la reforma pretende cambios sustanciales, éstos no terminan de satisfacer demandas que exigen un combate directo a la corrupción, mal que tanto aqueja a nuestra sociedad, y que se presenta con mayor fuerza en este sector derivado del capital que representa.

Aún se puede y debe mejorar; para ello se tienen que diseñar medios de control más efectivos, que fomenten en mayor medida la transparencia, pero sobre todo la rendición de cuentas. Así, tendremos instituciones sólidas, que fortalezcan nuestro sistema democrático y que generen confianza en la sociedad a partir de un adecuado desempeño de uno de los tantos sectores públicos del Estado, como el sector energético.

\section{BIBLIOGRAFÍA}

AdAm AdAm, Alfredo y Becerril LozAdA, Guillermo. 2003. Fiscalización y control gubernamental en México, México, Instituto Mexicano de Contadores Públicos, A. C.

Aguirre Romero, Lilia. 2015. "El efecto de la fiscalización bajo la perspectiva del desarrollo institucional", Revista de Administración Pública, 2(L), mayo-agosto.

Aragón, Manuel. 2002. Constitución. Democracia y control, México, UNAM, Instituto de Investigaciones Jurídicas.

BRIZIO RoDRÍGUEZ, Guillermo. 2008. "La auditoría, la transparencia y la rendición de cuentas", Revista de Administración Pública, XLIII, septiembre-diciembre.

Coldwell, Joaquín Pedro. 2014. "La propuesta del gobierno federal para la reforma energética de México", en GALlardo, Adrián y MORA, Luz María de la (coords.), Reforma energética, motor de crecimiento económico y bienestar, México, Fundación Colosio-Porrúa. 
FERnÁNDEZ RuIZ, Jorge. 2016. Derecho administrativo y administración pública. 7a. ed., México, Porrúa.

FOX, Jonathan. 2008. "Transparencia y rendición de cuentas", en ACKERMAN, John (coord.), Más allá del acceso a la información, transparencia, rendición de cuentas y Estado de derecho, México, Siglo XXI.

GALLARDO, Adrián. 2014. "Una reforma para el crecimiento económico y el bienestar", en Gallardo, Adrián y MORA, Luz María de la (coords.), Reforma energética, motor de crecimiento económico y bienestar, México, Fundación Colosio-Porrúa.

GonZÁLEZ, Juan José. 2017. Nuevo derecho energético mexicano, México, UAM. LANZ CÁrdenas, José Trinidad. 1987. La contraloría y el control interno en México, México, Fondo de Cultura Económica.

Loewenstein, Karl. 1976. Teoría de la Constitución, trad. de Alfredo Gallego Anabitante, Barcelona, Ariel.

LÓPEz TOACHE, Vania et al. 2018. "Las asociaciones público-privadas en México: corrupción estructural, subcontratación y endeudamiento", Actualidad Económica, núm. 95, mayo-agosto.

LOZOYA, Emilio, Pemex. 2014. "La industria petrolera y la reforma energética”, en GALLARDO, Adrián y MORA, Luz María de la (coords.), Reforma energética, motor de crecimiento económico y bienestar, México, Fundación Colosio-Porrúa.

Luna Pla, Issa. 2012. "Transparencia y rendición de cuentas", Seminario Internacional de Acceso a la Información, Protección de Datos Personales y Rendición de Cuentas del Poder Judicial de la Federación, México, Suprema Corte de Justicia de la Nación.

MANJARREz RiverA, Jorge. 2003. La construcción democrática de la rendición de cuentas y la fiscalización en la administración pública de México: 1997-2001, México, Instituto Nacional de Administración Pública.

MÁrQUeZ GómeZ, Daniel. 2003. Los procedimientos administrativos materialmente jurisdiccionales como medios de control en la administración pública, México, Instituto de Investigaciones Jurídicas, UNAM.

MÁrQUez Gómez, Daniel. 2005. Función jurídica de control de la administración pública, México, Instituto de Investigaciones Jurídicas, UNAM.

MEDina EsTRADA, Rubén. 2015. "El valor público de la fiscalización en México", Revista de Administración Pública, 137, vol. L, núm. 2, mayoagosto. 
MERINO, Mauricio. 2008. "La transparencia como política pública", en ACKERMAN, John (coord.), Más allá del acceso a la información, transparencia, rendición de cuentas y Estado de derecho, México, Siglo XXI.

Merino, Mauricio et al. 2016. "Por un sistema de rendición de cuentas", en Peschard, Jacqueline, Hacia el sistema nacional de transparencia, México, UNAM, Instituto de Investigaciones Jurídicas.

Mijangos Borja, María de la Luz. 1996. "Control del gasto público", Boletín Mexicano de Derecho Comparado, núm. 87.

Miranda Olivo, Marlen. 2015. "Las empresas productivas del Estado, análisis de su régimen jurídico y comparativo con las sociedades anónimas", Amicus Curiae, 3(1), enero-abril.

Monsiváis Carrillo, Alejandro. 2005. "Rendición de cuentas, justificaciones públicas y democracia. Una perspectiva deliberada", en Monsiváis G., Alejandro (comp.), Políticas de transparencia: ciudadanía y rendición de cuentas, México, Instituto Federal de Acceso a la Información Pública.

MORGAN Ríos, Rafael. 2008. "Una cuenta que se empieza a saldar. Transparencia y rendición de cuentas", Revista de Administración Pública, número especial, XLIII, septiembre-diciembre.

Olivas Gastélum, Ramón. 2017. “¿Qué hemos aprendido con la reforma energética? Lecciones y retos para una nueva administración”, disponible en: https://imco.org.mx/indices/memorandum-para-el-presidente-2018-2024/capitulos/garantizar-la-continuidad-de-las-reformas-educativay-energetica/que-hemos-aprendido-con-la-reforma-energetica-lecciones-y-retos-para-una-nueva-administracion.

Peralta Hernández, Elsa Bibiana. 2015. "Fiscalización, control y auditoría gubernamental", Revista de Administración Pública, 2(L), mayoagosto.

Romero GudiÑO, Alejandro. 2019. Teoría, evidencia y prospectiva de la fiscalización y rendición de cuentas en México, México, INAP.

SAlGado SÁNCHEZ, Raquel. 2006. "Rendición de cuentas y transparencia en organizaciones campesinas", en HERnÁNDEZ BAQUEIRO, Alberto (coord.), Transparencia, rendición de cuentas y construcción de confianza en la sociedad y el Estado mexicanos, México, Instituto Federal de Acceso a la Información Pública.

SchedLER, Andreas. 2008. “Qué es la rendición de cuentas”, en SosA, José (comp.), Transparencia y rendición de cuentas, México, Siglo XX.

Esta obra está bajo una Licencia Creative Commons

Atribución-NoComercial-SinDerivar 4.0 Internacional, IIJ-UNAM.

Boletín Mexicano de Derecho Comparado, núm. 157, enero-abril de 2020, pp. 123-168. 
Sepúlveda Toledo, Maylí. 2005. "Visibilidad y control: la rendición de cuentas en las organizaciones civiles", en Monsiváis C., Alejandro (comp.), Políticas de transparencia: ciudadanía y rendición de cuentas, México, Instituto Federal de Acceso a la Información Pública.

Serra Rojas, Andrés. 2016. Derecho administrativo, 29a. ed., México, Porrúa.

Toledo Guerrero, Gabriel. 2016. Corrupción en el sector energético mexicano: propuestas y recomendaciones, México, Wilson Center.

Ugalde, Luis Carlos. 2015. Rendición de cuentas y democracia. El caso de México, México, Instituto Nacional Electoral.

VÁzQuez Sentíes, Luis. 2015. "Prólogo", en RodríGuez Dávalos, Jesús (comp.), Reforma energética regulación, México, Rodríguez Dávalos Abogados, Miguel Ángel Porrúa.

VEGA RodríGUEZ, Francisco Javier. 2018. "Fiscalización superior, rendición de cuentas y combate a la impunidad", Revista de Administración Pública, 2, LIII, mayo-agosto.

Recursos electrónicos

DeGlaración de los Dereahos Del Hombre y Del Ciudadano, s. d., disponible en: https://wrwre.conseil-constitutionnel.fr/sites/default/files/ as/root/bank_mm/espagnol/es_ddhc.pdf.

GOBIERnO CORPORATIVO, s. d. "Bolsa Mexicana de Valores", disponible en: https://wrwre.bmv.com.mx/es/mi-empresa-en-bolsa/gobierno-corporativo.

Gobierno DE MÉXICO. 2014. "Estrategia Nacional de Energía”, disponible en: https://wrwr.gob.mx/cms/uploads/attachment/file/214/ENE.pdf.

INTOSAI. s. d. "Glosario de términos de las Directrices de auditoría financiera de la INTOSAI", disponible en: http://wrerr.intosai.org/es/ issai-executive-summaries/detail/issai-1003-glosario-de-terminos-de-las-directrices-de-auditoria-financiera-de-la-intosai.html.

INTOSAI. s. d. "ISSAI 4100", disponible en: http://wrerr.intosai.org/es/ issai-executive-summaries/detail/issai-4100-directrices-para-las-auditorias-decumplimiento-realizadas-separadamente-de-la-auditori.html.

MÉxico Gobierno DE LA REPúblicA. s. d. "Reforma energética", disponible en: https://wwrw.gob.mx/cms/uploads/attachment/file/10233/Explicacion_ampliada_de_la_Reforma_Energetica1.pdf. 
SECRETARÍA DE GOBERnACión. 2013. "Proyecto de iniciativa de reforma a los artículos 27 y 28 de la CPEUM del Ejecutivo Federal”, disponible en: http://wrwrordenjuridico.gob.mx/Constitucion/reformas/IEF20122013.pdf.

SFP. s. d. Disponible en: http://pcop.funcionpublica.gob.mx/index.php/conocela-sfp.html.

SENADO DE LA REPública. 2014. "Oficio de iniciativa de decreto por el que se expiden la Ley de Petróleos Mexicanos y la Ley de la Comisión Federal de Electricidad y se reforman y derogan diversas disposiciones de la Ley Federal de las Entidades Paraestatales, la Ley de Adquisiciones, Arrendamientos y Servicios del Sector Público y la Ley de Obras Públicas y Servicios Relacionados con las mismas", disponible en: http://infosen.senado.gob.mx/sgsp/gaceta/62/2/2014-04-30-1/assets/ documentos/Ley_Petroleos_Mexicanos.pdf

TiPOS DE AUDiTORÍA. s. d. "Auditoría Superior de la Federación", disponible en: https://wrereasf.gob.mx/Section/53_Tipos_de_auditorias_desarrolladas. 